evolved or absorbed on the addition of one mol of solvent to an infinite amount of solution. This quantity can, obviously, not be measured directly. A knowledge of this reversible heat of dilution can, however, ustrally be obtained by studying the effect of adding varying amounts of solvent to the solution. On dividing the values of the resulting heat effects, by the corresponding number of mols of solvent added, a series of molal heats of dilution is obtained. If these molal heats of dilution are plotted as ordinates against the corresponding amounts of solvent as abcissae a straight line is usually obtained which, when extended to the zero ordinate, gives the quantity sought.

The results of a series of measurements of the dilution of $3 \mathrm{~N}$ ethyl alcohol solutions are given in Table IV, and plotted in Fig. 6 . The circles around the points in the figure represent the error that would be produced by an error of $0.000 r^{\circ}$ in the temperature measurement. This represents but a small portion of the data in hand. A forthcoming article will give further data and a theoretical discussion of the results.

TABLE TV.

Heats of Dilution of $3 N$ Ethyl Alcohol Solutions.

\begin{tabular}{|c|c|c|c|}
\hline $\begin{array}{l}\text { Wt. of solutions. } \\
\text { G. }\end{array}$ & $\begin{array}{c}\text { Wt. of water. } \\
G \text {. }\end{array}$ & $\begin{array}{l}\text { Heat of diln. } \\
\text { Calories. }\end{array}$ & $\frac{\text { Heat of diln. }}{\text { Mols. water }}$ \\
\hline 96 II & 801.24 & $88 \mathrm{I} . \mathrm{I}$ & I9. $8 \mathrm{I}$ \\
\hline 9612 & 800.96 & 88 I. 2 & I 9.82 \\
\hline 9612 & $600.9 \pi$ & 676.8 & 20.30 \\
\hline 96 II & 600.39 & 676.3 & 20.30 \\
\hline 96 II & 400.48 & 463.3 & 20.84 \\
\hline 9610 & 400.95 & 463.8 & 20.84 \\
\hline $96 \mathrm{II}$ & $200.6 \mathrm{I}$ & 237.4 & 21.32 \\
\hline 9612 & $200 . \mathrm{II}$ & $e^{\prime \prime}$ heat of $d$ & $\begin{array}{r}21.37 \\
\mathrm{n}, \quad 21.80\end{array}$ \\
\hline
\end{tabular}

A calorimeter designed for the accurate measurement of heats of dilution, based on a modification of the adiabatic principle, is described. The data obtained in a series of determinations of the heats of dilution of $3 N$ ethyl alcohol solutions are given and the "reversible" heat of dilution of this solution is calculated.

URBANA, ILLINOIS.

[CONTRIBUTION FROM THE CHEMICAL, LABORATORY OF THE UNIVERSITY OF CAIIFORNIA.]

\title{
A STUDY OF THE SYSTEM ANILINE-HEXANE.
}

By Donald B. Keyes and Joki, H. Hildegrand.

Received August 6, 1917.

A successful method for accounting for the deviation from Raoult's law is of extreme importance to nearly all questions involving the theory of solutions. Two radically different methods for doing this have been 
proposed: one, advocated by Dolezalek ${ }^{1}$ and others, ascribes all deviations from this law to what may be termed chemical changes, such as association, dissociation, and compound formation; the other method is based upon the van der Waals theory and has been advocated notably by van Laar. ${ }^{2}$ These two methods have been discussed by one of us in a paper entitled "Solubility."3 It was there pointed out that while the assumption of association where polar and non-polar liquids are mixed often enables one to account formally for positive deviations from Raoult's law, in the case of mixtures of non-polar liquids showing considerable positive deviation the degree and type of dissociation that would have to be assumed in order to conform to the mass law may become absurd. The present investigation was undertaken in order to discover a mixture of normal liquids that would deviate from Raoult's law to the extent of forming two liquid phases, and to measure properties of the mixtures which might be concerned with the explanation of this deviation.

In seeking such a mixture the criteria used for normal behavior were: a low dielectric constant, a normal temperature coefficient of "molecular surface energy" and "molecular cohesion," 4 and a normal entropy of vaporization. ${ }^{5}$

In our selection of pairs of liquids to test for partial miscibility we were guided by wide divergence in boiling points, freezing points, or surface tensions. The determining nature of internal pressure as shown in the paper on "Solubility" already referred to was not discovered until after this part of the work was completed, but what was learned could have been predicted on that basis, as will be shown later. Where freezing of one or both components did not interfere, tests were made at temperatures as low as $-80^{\circ}$. About 500 different pairs of normal liquids were tested, and the only ones that gave systems with two liquid phases were the following: aniline and pentane, or hexane; naphthylamine and pentane, or hexane. A case of incomplete miscibility cited in Van Nostrand's "Annual," ethyl myristate in ether, proved to be incorrect.

There is no question about the normal behavior of hexane, the saturated hydrocarbons all being entirely normal according to whatever criteria are chosen. The same is not true, however, with regard to aniline and naphthylamine, both of which show a small degree of association or

${ }_{1}^{1}$ Dolezalek, Z. physik. Chem., 64, 730 (1908).

${ }^{2}$ Van Laar, Ibid., 72, 723 (I9IO); 83, 599 (I9I3).

${ }^{3}$ J. H. Hildebrand, ThIS Journal, 38, I452 (IgI6), see especially pp. 1456-8; see also J. H. Hildebrand, Ibid., 35, 50I (I913); Trans. Am. Electrochem. Soc., 22, 3 I 9 (I9r3); E. D. Eastman and J. H. Hildebrand, Thrs Journal, 36, 2020 (rgr4); Ibid., 37,2452 (1915).

4 See extensive values by Walden, Z. physik. Chem., 66, 438 (1909); 70, 579 (1910); 82,292 (1913).

$5 \mathrm{~J}$. H. Hildebrand, ThIS JoURNaI, 37,970 (I915). 
polarity. The extent of this is indicated by the following comparison of hexane, aniline and alcohol, the last being a typically associated or polar liquid:

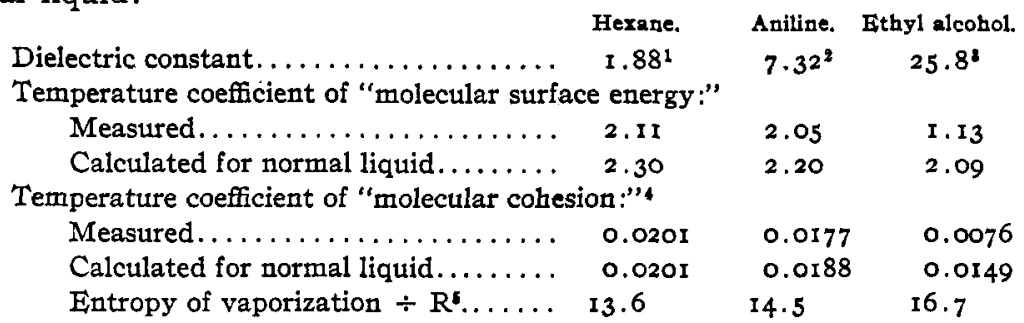

The selection of aniline as a non-associated liquid is evidently not free from objection. It is practically certain, however, that the magnitude of the deviations from additivity of the properties of its mixtures with hexane, as shown below, are far greater than can rightly be accounted for by its very moderate association.

\section{Purification of Aniline and Hexane.}

Hexane, made from petroleum, was purified by distillation with alkaline permanganate and then by redistillation from calcium chloride; the fraction boiling between $68.00^{\circ}$ and $69.75^{\circ}$ was taken. The boiling point of $n$-hexane is $69.0^{\circ}$. Its isomers boil at $64^{\circ}, 62^{\circ}, 5^{\circ}$, and $50^{\circ}$, respectively. ${ }^{\circ}$ As the physical properties of these isomers vary but little, such a fraction as taken was satisfactory for these measurements. In a second purification the fraction between $67.5^{\circ}$ and $68.5^{\circ}$ was used.

The aniline used, a commercial "Pure Aniline," was dissolved in hydrochloric acid, the nitro bodies distilled off with steam, the solution made alkaline and the aniline driven off. Sticks of sodium hydroxide were added to the oil to dry it, the mixture shaken, and the sticks removed. The aniline was then distilled in vacuo.

It was thought that the following properties of the system anilinehexane might prove valuable in accounting for its deviation from Raoult's law: mutual solubility, change of volume on mixing, heat of mixing, surface tension, vapor pressure and compressibility. Time did not permit the investigation of one other property of theoretical interest, $i$. e., the coefficient of expansion.

1 At $17^{\circ}$, Nernst, Z. physik. Chem., 14, 622 (1894).

${ }^{2}$ At $18^{\circ}$, B. B. Turner, Ibid., 35, 385 (1900).

${ }^{8}$ At $20^{\circ}$, Abegg and Seitz, Ibid., 29, 242 (1899).

4 Walden and Swinne, Ibid., 82, 296 (1913).

3 Hildebrand, ThIs JourNaI, 37, 970 (1915). The value for aniline has been calculated from the vapor-pressure measurements of Kahlbaum, $Z$. physik. Chem., 26, 603 (1898).

'Meyer and Jacobson, "Lehrbuch des organischen Chemie," I, Pt.' I, I64 (I906-7). 


\section{Solubility.}

The solubility of each component in the other was found by determining the temperature at which the separation of a second liquid phase took place from a mixture of known composition.

A small Dewar tube was used, having a capacity about $30 \mathrm{cc}$. and provided with a tinfoil-covered stopper holding a small thermometer. Varying amounts of aniline and hexane were introduced and weighed in the apparatus, the tube closed, and then warmed gently in a bath, shaking continually until the two phases merged into one. This temperature at which this took place was read, also that at which the first permanent cloud appeared as the solution was cooled down. Between these temperatures lay the temperature of complete miscibility for this particular composition. The maximum difference ever found between these two temperature readings was $0.6^{\circ}$, making the maximum error in the average value $\pm 0.3^{\circ}$. Plotting these average temperatures against the percentage composition by weight gave the solubility curve.

The thermometer used was standardized at the transition temperatures of $\mathrm{Na}_{2} \mathrm{SO}_{4} \cdot \mathrm{TOH}_{2} \mathrm{O},-32.38^{\circ}$ and $\mathrm{NaBr} .2 \mathrm{H}_{2} \mathrm{O},-50.67^{\circ} .{ }^{1}$

Allowance was made for the hexane in the vapor state above the liquid phases, in order to get the true percentage composition of the solution. Below are given the data found.

$\begin{array}{cccc}\% \text { Hexane. } & \begin{array}{c}\text { Temp. of complete } \\ \text { miscibility. }\end{array} & \% \text { Hexane. } & \begin{array}{c}\text { Temp. of complete } \\ \text { miscibility. }\end{array} \\ 9.6 & 26.0^{\circ} & 35.9 & 59.2 \\ 14.8 & 43.9 & 41.6 & 59.4 \\ 16.3 & 45.9 & 48.0 & 59.6 \\ 20.0 & 49.9 & 62.9 & 57.9 \\ 21.0 & 5 \mathrm{I} .4 & 73.1 & 53.9 \\ 27.2 & 56.0 & 80.6 & 47.2 \\ 31.0 & 58.2 & 88.1 & 35.6 \\ 34.6 & 58.2 & 93.8 & 16.5\end{array}$

These results are plotted in Fig. I.

\section{Change of Volume on Mixing.}

A specially constructed dilatometer, previously designed by one of us, and shown in Fig. 2, was used to determine the change of volume on mixing. It consisted of two glass bulbs of different capacity connected by a U-tube. At the top of each bulb was a capillary tube provided with a scale. The tubes were bent over at an angle to the vertical axis of the bulbs. The reversed pear shape of the latter allowed a wide variation in the ratio between the amount of liquid in the bulbs to be obtained by varying the quantity of mercury. After introducing the required amount of mercury the bulbs were filled nearly full of the respective liquids successively, by the aid of a funnel thrust into the upper portion of the stem,

1 T. W. Richards, Proc. Amer. Acad. Arts Sci., 34, 277 (1899); 4I, 435 (1906). 


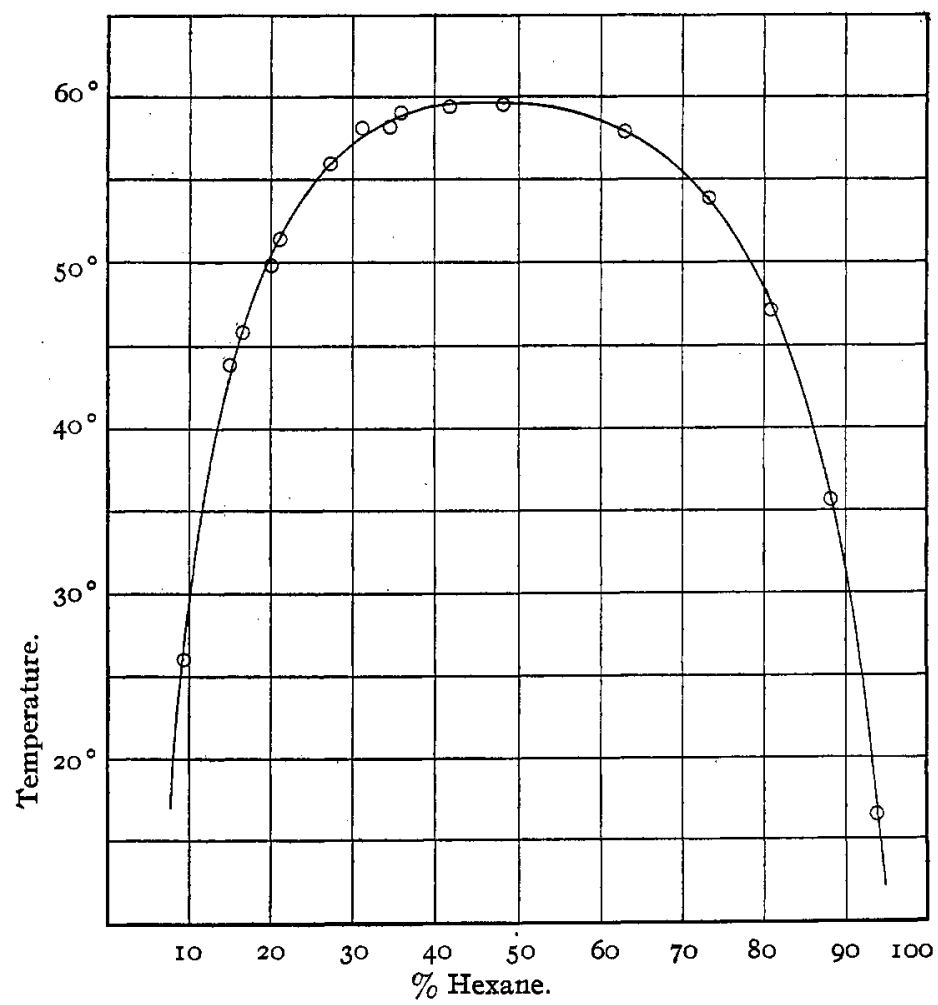

Fig. I.

and held by rubber tubing on the outside. The air in the bulb was removed by alternately blowing and sucking on the opposite stem. The dilatometer was then placed in a brass frame designated to support it without strains and immersed up to the base of the stems in the water of the thermostat. The thermostat was kept at $40.0^{\circ}$. By means of a very fine capillary tube inserted into the stems of the bulbs, the position of the liquid column in each was adjusted so as to bring the readings near the middle of the scale. The stems were then closed to prevent loss of liquid during the later shaking. When temperature equilibrium was reached the sum of the two readings remained constant. The liquids were mixed by tilting the brass frame which held the dilatometer and causing the mercury to flow back and forth between the bulbs. The angle which the stems formed with the axes of the bulbs allowed the latter to be in a horizontal position for mixing their contents while the stems still projected upwards above the liquid in the thermostat. The mercury was finally brought to the same level in both bulbs so as to equalize the pressure throughout. Some heat effect accompanied the mixing, and the apparatus was allowed to stand in the thermostat until the original tem- 
perature was restored before making any readings. Traces of gas might be evolved during the mixing, which would change the pressure in the apparatus and hence affect the volume of the liquid. On this account the stems were unsealed to restore atmospheric pressure before readings were made. The change of volume on mixing was calculated from the difference between the sum of the readings taken before and after mixing. The change in volume corresponding to the change in scale reading was found by the aid of a calibration of the graduated tubes. The total amount of liquid mixture was weighed and the percentage composition determined by finding

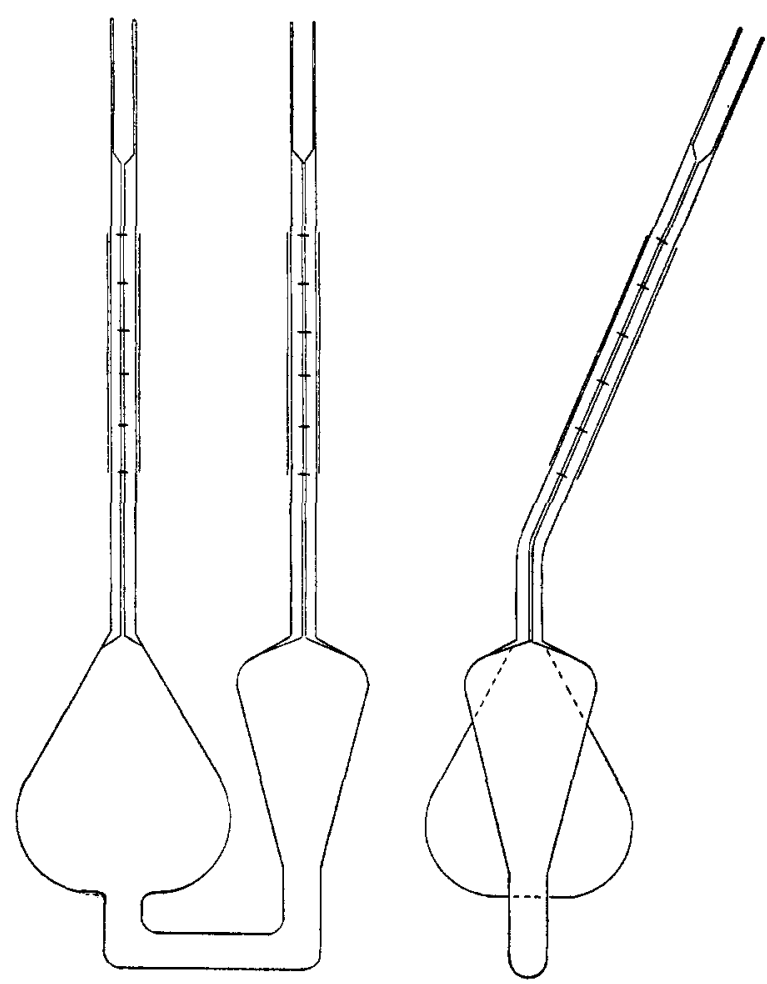

Fig. 2. the temperature of complete miscibility of the mixture, using the solubility curve previously drawn. The results were as follows:

$\%$ hexane in mixture......

Expansion on mixing, cc. per

8.3

I0.0

86.0 91.0

g. of mixture.......... $-0.001750-0.001880+0.000555+0.000478$

These results are shown graphically in Fig. 3.

\section{Heat of Mixing.}

A rough determination of the heat of mixing was made, using a silvered Dewar bulb as a calorimeter vessel and a Beckmann thermometer to record temperature changes. One liquid was contained in a sealed bulb inside of the other, the bulb being broken in order to mix the liquids.

The results were:

$\%$ hexane......................... $89.8 \quad 7.8$

Calories absorbed per g. of mixture............ $0.29 \quad 0.57$ 


\section{Surface Tension.}

The surface tension was determined by the rise in a capillary tube. Between the capillary tube and the walls of the containing tube was a distance of about $2.5 \mathrm{~cm}$., this distance being great in order to eliminate any capillary effect of the outer tube. ${ }^{1}$ The surface of the liquid was renewed by blowing into the instrument, forcing the liquid out of the top of the capillary tube, and then allowing it to drop back. A porcelain scale was wired on to the tube with platinum, and a platinum wire touched the surface of the liquid from below acting as an indicator for the zero

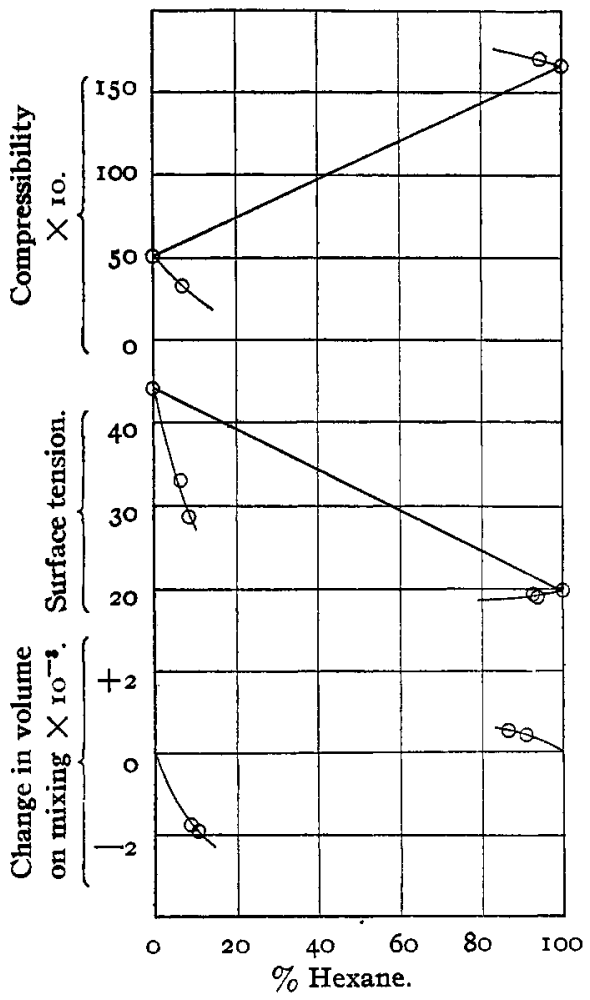

Fig. 3.

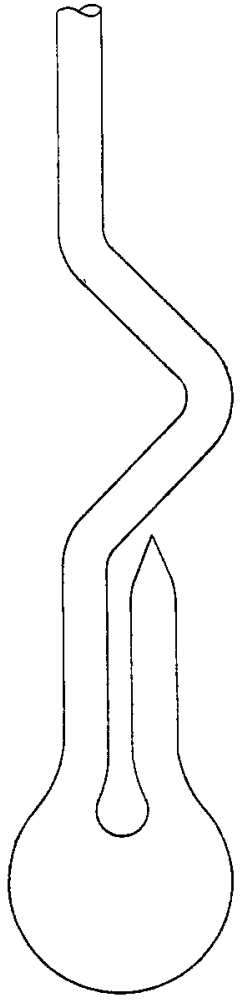

Fig. 4 .

point on the scale. The radius of the capillary tube was found by measuring the capillary rise of benzene, taken as 28.9 dynes per $\mathrm{cm}$. at $20^{\circ}$.

In a mixture such as this, where the liquids have widely different surface tensions, there is a difference between the surface tension as measured by dynamic or by static methods, due to the changed concentration of one component at the surface after sufficient time has elapsed. The figures here given represent the static values.

1 T. W. Richards and L. B. Coombs, This Journal, 37, 656 (1915). 
The following table contains the results of the measurements, which are also shown graphically in Fig. 3:

$\begin{array}{lllllll}\text { Hexane by weight, } \% \ldots \ldots \ldots \ldots \ldots & 0.0 & 6.6 & 8.0 & 92.4 & 93.2 & 100.0\end{array}$

$\begin{array}{llllllll}\text { Surface tension at } 25^{\circ} \ldots \ldots \ldots \ldots \ldots \ldots & 44 . I^{1} & 33.1 & 28.8 & 19.4 & 19.0 & 19.7\end{array}$

Hexane by volume, $\% \ldots \ldots \ldots \ldots \ldots . \quad 0.00 \quad 9.49 \quad 11.53 \quad 93.5 \quad 94.8 \quad 100.0$

\section{Vapor Pressure.}

The vapor pressure of hexane in equilibrium with the two saturated liquids was determined in an apparatus essentially the same as that used previously in this laboratory in measuring the vapor pressure of amalgams. ${ }^{2}$ The tubes shown in Fig. 4 were somewhat larger than those used in the amalgam work and the capacity of the bottom part was much increased by blowing it into a bulb. The manipulation was essentially the same as that previously described. The pressure of pure hexane was compared with that ${ }_{\mathrm{s}}$ of the three-phase system at $40^{\circ}$.

The results obtained, are given in the following table, and plotted against the composition in Fig. 5 :

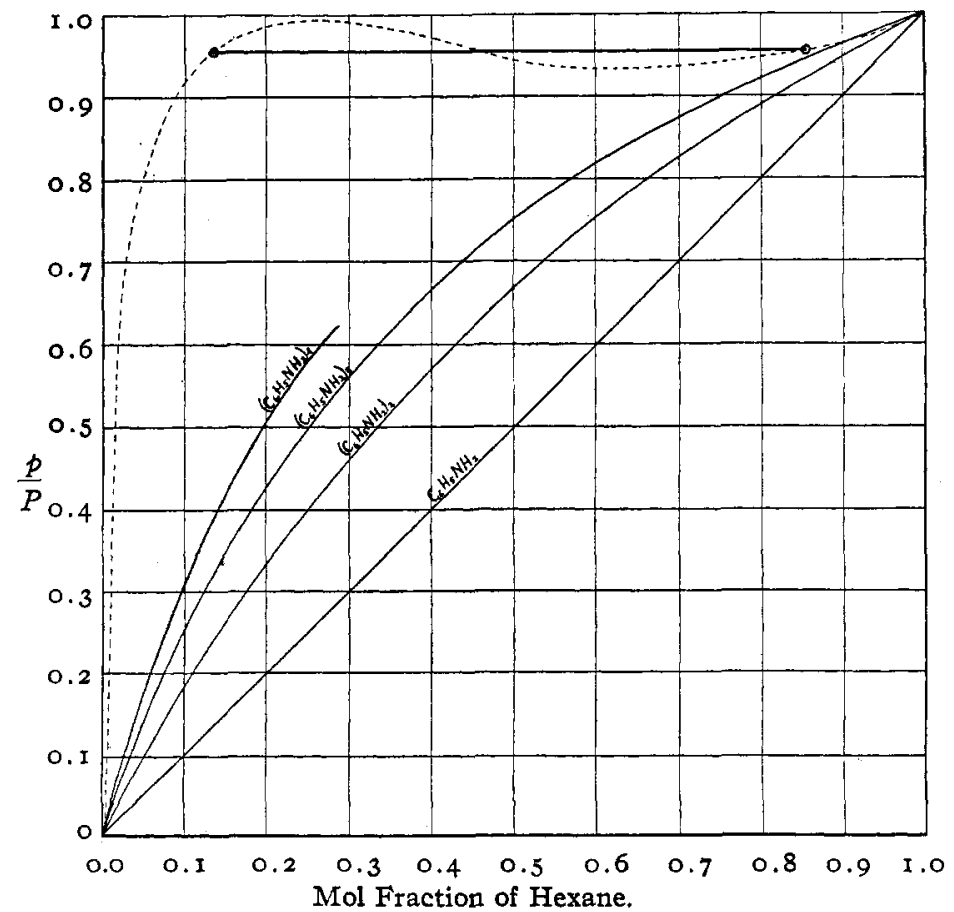

Fig. 5 .

${ }^{1}$ By extrapolation to $25^{\circ}$ the value of 43.2 dynes is obtained from measurements of Volkmann, Ann. physik., [3] 56, 457 (I895).

2 J. H. Hildebrand, Trans. Am. Electrochem. Soc, 22, 319 (1912); E. D. Eastman and J. H. Hildebrand, THIs JoURNaL, 36, 2020 (I914). 


$\begin{array}{ccc}\text { Pressure of the solutions, } \\ p(\mathbf{m m .}) . & \text { Pressure of pure herane, } & \\ \mathbf{P}(\mathrm{mm} .) . & p / \mathbf{P .} \\ 276.8 & 289 . I & 0.957 \\ 277.1 & 290.8 & 0.953 \\ 277.1 & 290.5 & 0.954 \\ 276.3 & 289.3 & 0.955 \\ 276.1 & 290.5 & 0.951 \\ 276.5 & 289.5 & 0.955 \\ 277.7 & 290.5 & 0.956 \\ 278.0 & 291.5 & 0.954 \\ 278.1 & 291.0 & 0.956 \\ 277.5 & 290.5 & 0.955 \\ & & \end{array}$

The vapor pressure of pure aniline at $40^{\circ}$ is $\mathrm{I} \mathrm{mm}$., so that the pressures given are practically the partial pressures of hexane.

Since the vapor pressure of the system containing two liquid phases only was determined, the composition of these phases was fixed by the temperature, and is found, from the solubility curve, to be as follows:

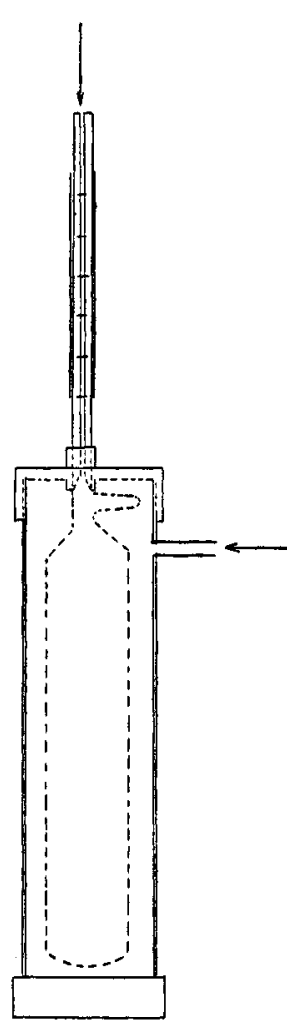

Fig. 6. aniline layer, $13.5 \%$ hexane; hexane layer, $85.4 \%$ hexane. Since the molecular weights of hexane and aniline are nearly identical, the weight per cent. and the mol per cent. are almost the same.

This gives altogether four points on the vaporpressure composition curve. The complete curve would be of the type shown in Fig. 6 by the dotted line. It is evident that for both phases there is a considerable positive deviation from Raoult's law.

\section{Compressibility.}

The compressibility was determined in the apparatus depicted in Fig. 6. The liquid was enclosed in a glass tube contained within a steel bomb. The space between the tube and the jacket was filled with water. The same pressure was applied to the inner and outer liquid, thus avoiding any strain to the glass tube, and the change in volume of the inner liquid read upon the graduated stem. This stem protruded through the cap of the steel jacket, and the joint was made tight by means of a rubber stopper and rubber cement. The cap was made gas-tight by the aid of a lead washer.

The determinations were carried out in a thermostat at $40^{\circ}$, the same temperature at which the vapor pressure and the change of volume on mixing were determined. 
The pressure gauge used was calibrated by comparison with a mercury column.

Some trouble was experienced on account of air bubbles collecting within the apparatus, and which, though not visible, caused an erratic behavior. All liquids had to be boiled out within the apparatus itself before the experiment.

The results are shown in the following table and also in Fig. 3:

COMPRESSIBILITIES.

\begin{tabular}{cccc}
\multicolumn{5}{c}{ Change in Volume per Cc. per Atmosphere $\times$ I0 } \\
Hexane. & $94.0 \%$ hexane. & $7.0 \%$ hexane. & Aniline. \\
I68 & I70 & 32 & 51.2 \\
I72 & 166 & 33 & 51.2 \\
I64 & I74 & - & - \\
I68 & I70 & Mean, 33 & Mean, $51.2^{1}$ \\
I64 & - & &
\end{tabular}

\section{Discussion of Results.}

A fuller discussion of the significance of the measurements here presented will be postponed until certain other data have been secured. At present we will be content merely to point out the theoretical connection between the deviation of the mixture from Raoult's law and the other properties observed.

It may be noted, first, that the great deviation of the vapor pressure from Raoult's law is in harmony with the great difference between the internal pressure of the two liquids as shown in the table of internal pressures given in the paper on "solubility," already referred to. If the importance of internal pressure in determining the vapor pressures of mixtures had been understood at the time this investigation was begun, a great deal of the work of searching for liquids incompletely miscible might have been avoided. It must be admitted that a certain part of the deviation in the present instance must be attributed to the slightly polar character of aniline, and not entirely to the great difference in internal pressures of aniline and hexane, but this effect cannot be very great. In Fig. 5, in addition to the actual vapor pressures, are shown the curves that would result if Raoult's law were obeyed, and assuming first that the aniline is unassociated, the simple linear vapor-pressure relationship, second, that it is completely associated to double molecules, but which obey Raoult's law, third and fourth, that it is associated to form $\left(\mathrm{C}_{6} \mathrm{H}_{5} \mathrm{NH}_{2}\right)_{3}$ and $\left(\mathrm{C}_{6} \mathrm{H}_{5} \mathrm{NH}_{2}\right)_{4}$, respectively. It would be expected that any such complex molecules would dissociate as the percentage of hexane is increased, giving lower values of the vapor pressure of hexane at the

1 Tyrer, J. Chem. Soc., 105, 2534 (1914), gives the compressibility of aniline as 51.04 at $40^{\circ}$. 
right hand and of the curves in Fig. 5 than those drawn; hence these curves indicate maximum values.

It is obvious that none of these assumptions at all approach in magnitude the vapor pressures actually observed, hence any reasonable assumption regarding the association of aniline cannot account for the whole divergence from Raoult's law, which is rather to be attributed chiefly to the great difference in internal pressures of the two liquids.

The deviations from Raoult's law are to be interpreted as a function of the internal pressures of the liquids is supported by the fact that the surface tension of the mixtures is less than additive, indicating that the molecular forces in the mixture are less than additive, which would lead us to expect that the tendency of molecules to escape from the mixture would be greater than that calculated on an additive basis, $i . e$, as given by Raoult's law.

The absorption of heat when the liquids are mixed also indicates a decrease in internal pressure and a corresponding effect on the vapor pressure.

It was somewhat surprising to find that, whereas the formation of a mixture rich in hexane was attended by an expansion, which might be expected to result in a lessening of the attractive forces, in harmony with the foregoing effects, the formation of a mixture rich in aniline was attended by a considerable contraction. In nearly all cases a vapor pressure greater than indicated by Raoult's law is accompanied by an expansion on mixing, and vice versa. ${ }^{1}$ The changes in volume here found may be connected with the similar deviation from additivity shown by compressibility. The mixture rich in hexane is more compressible, and the one rich in aniline is less compressible than the corresponding additive values would indicate. The fact that hexane is very compressible may mean that when it is put in small amount into a liquid of high internal pressure its molecules are compressed, giving a decrease in volume and showing also a greater resistance to further compression. This accords with the observations of Dawson ${ }^{2}$ and Tyrer, ${ }^{3}$ who found that certain organic solutes show contractions on going into solution in compressible solvents like ether and heptane, and expansions when dissolving in less compressible solvents like nitrobenzene.

\section{Summary.}

A large number of normal or nearly normal liquids were investigated in a search for pairs that would not be completely miscible. Aniline and hexane proved to furnish the nearest approach to the desired conditions.

The following properties were investigated: mutual solubility, vapor

1 Compare, for example, vapor pressures by Zawidzki, Z. physik. Chem., 35, 129 (1900), with volumes by Hubbard, Ibid., 74, 217 (I910).

${ }^{2}$ Dawson, $J$. Chem. Soc., 97, 1048 (1910).

- Tyrer, Ibid., 97, 2620 (1910). 
pressure, heat of mixing, surface tension, change of volume on mixing, and compressibility.

It has been shown that there is a strong positive deviation of the vapor pressure from Raoult's law, that the formation of mixtures is accompanied by an absorption of heat, by an expansion for mixtures rich in hexane and a contraction for those rich in aniline, that the surface tension of the mixture is less than additive, and that the compressibility of a mixture rich in hexane is greater than additive, while that of one rich in aniline is less than additive.

The theoretical bearing of the foregoing facts has been discussed briefly.

BERRELLIY, CALIFORNIA.

[CONTRIBUTION FROM THE Chemical LABORATORY, UnIVERSity OF Illinois.]

THE NOMON-A CALCULATING DEVICE FOR CHEMISTS.

By Horace G. DERTNG.

Received August 7, 1917.

The slide-rule has never been in such general use among chemists as among engineers, doubtless for the reason that many of the calculations of chemistry demand a higher degree of accuracy than that obtainable with the ordinary form of this instrument. There seems to be a real demand for an instrument at once more accurate than a slide-rule and cheaper, handier, and more portable than a calculating machine.

A calculating chart designed by the writer, ${ }^{1}$ to which the name nomon (i. e., nomographic reckoner) has been given, seems to satisfy these requirements. It will multiply, divide, square, cube, and extract square roots and cube roots, giving results to four figures, with an average error of about one unit in the fourth place, a degree of precision about five or ten times that of an ordinary ten-inch rule. For solving proportions it is not so convenient as a slide-rule, but one should remember that in an ordinary chemical proportion two of the terms can usually be combined in a single constant, thus reducing the calculation to a simple multiplication or division.

In the construction of the nomon the logarithmic principle at the basis of the slide-rule has been abandoned entirely, and resort had to a new combination of graphical principles, the mathematical details of which will be published elsewhere. The present paper is intended merely to indicate the method of using the chart, and the special advantages that it offers in chemical calculations.

To multiply two numbers together, find one of them, neglecting decimal points, on the scale at the left of the chart, called the principal scale (Fig. I). Find the other number, after dropping its first figure, on the inclined scale at the right. Connect the two points thus located by means of a

${ }^{1}$ Published by the University Press, Urbana, Ill. 